\title{
Modification of Sulfated Arabinogalactan with Amino Acids by Ion Exchange Method
}

Natalia Yu. Vasilyeva ${ }^{a, b}$, Alexander V. Levdansky ${ }^{\mathrm{a}}$, Alexander S. Kazachenko ${ }^{\mathrm{a}}$, Galina P. Skvortsova ${ }^{a}$ and Boris N. Kuznetsov*a,b ${ }^{a}$ Institute of Chemistry and Chemical Technology SB RAS 50/24 Akademgorodok, Krasnoyarsk, 660036, Russia

${ }^{b}$ Siberian Federal University 79 Svobodny, Krasnoyarsk, 660041, Russia

Received 17.11.2015, received in revised form 26.01.2016, accepted 12.02.2016

The new method of sulfated arabinogalactan modification by amino acids (glycine and ornithine) based on the ion exchange procedure was developed. The composition and structure of the reaction products obtained by interaction of sulfated arabinogalactan with amino acids were studied by elemental analysis and FTIR spectroscopy.

Keywords: sulfated arabinogalactan, ion exchange, glycine, ornithine, composition, structure.

DOI: $10.17516 / 1998-2836-2016-9-1-20-28$.

(C) Siberian Federal University. All rights reserved

* Corresponding author E-mail address: inm@icct.ru 


\section{Модификация сульфатированного \\ арабиногалактана аминокислотами \\ методом ионного обмена}

Н.Ю. Васильева ${ }^{\mathrm{a}, \boldsymbol{\sigma}}$, А.В. Левданский А.С. Казаченко ${ }^{a}$ Институт химии и химической технологии СО РАН Россия, 660036, Красноярск, Академгородок, 50/24

${ }^{6}$ Сибирский федеральный университет Россия, 660041, Красноярск, пр. Свободный, 79

Предложен новый способ модификации сульфатированного арабиногалактана аминокислотами с глицином и орнитином, основанный на использовании метода ионного обмена. Методами элементного анализа и ИК-спектроскопии изучен состав и строение продуктов взаимодействия сульфатированного арабиногалактана с аминокислотами.

Ключевые слова: сульфатированный арабиногалактан, ионный обмен, глицин, орнитин, состав, строение.

\section{Введение}

Производные аминокислот постоянно востребованы благодаря своему исключительно широкому спектру действия и входят в состав лекарственных препаратов, предназначенных для лечения разнообразных заболеваний [1,2].

Большой интерес представляют полисахарид-аминокислотные производные [3-6], в которых аминокислота присоединена к полимеру разными типами химической связи. Химическая фиксация лекарственных субстанций на полисахаридной матрице позволяет создавать препараты пролонгированного действия с низкой токсичностью и необходимым балансом липофильно-гидрофильных свойств [6].

Использование такой химически модифицированной природной матрицы, как сульфатированный арабиногалактан, который обладает антикоагулянтной и гиполипидемической активностью, является потенциальным гепариноидом, а также самостоятельным антимикробным агентом $[7,8]$, имеет большие перспективы по сравнению с другими матрицами вследствие того, что этот модифицированный биополимер практически нетоксичен, водорастворим, а наследование наноструктурированной морфологии исходного арабиногалактана $(\mathrm{AG})[8,9]$ позволяет надеяться на сохранение его иммуномодуляторных и трансмембранных свойств в синтезе новых физиологически активных полимеров.

Известно, что сульфатированные полисахариды, будучи полиэлектролитами, способны взаимодействовать с окружающими их противоионами с образованием разнообразных молекулярных комплексов [10-15]. Наиболее хорошо изученным примером такого взаимодействия являются разнообразные комплексы гепарина [10, 12-16]. Как известно, гепарин кислый серосодержащий гликозаминогликан, использующийся в клинической практике в 
качестве прямого антикоагулянта [16]. По отношению к биологически активным веществам эндогенной или экзогенной природы он обладает моделирующим свойством. Связываясь с гепарином, эти вещества могут менять свою активность (например, усиливая или ослабляя свои типичные эффекты) или кардинально изменять свои функции $[14,15]$. Молекулярные комплексы гепарина с аминокислотами [15] обладают мощным антикоагулянтным эффектом, кроме того, они и антиагреганты, и фибринолитики. Отдельно компоненты комплекса такого набора свойств не проявляют. Нейтрализация антикоагулянтного эффекта гепарина также происходит за счет электростатического взаимодействия между отрицательно заряженным полисахаридом и положительно заряженным протамин-сульфатом с возникновением комплекса [16].

Все эти данные позволяют предположить, что модификация сульфатированного арабиногалактана, являющегося гепариноидом, аминокислотами может придать ему иную физиологическую активность.

Сульфатированный AG, как и гепарин, будучи полианионом, может взаимодействовать с положительно заряженными соединениями, например с протонированной формой аминокислот. В связи с этим существует принципиальная возможность его модификации аминокислотами методом ионного обмена. В настоящее время модифицирование сульфатированного AG аминокислотами неизвестно. Обычно ионообменные смолы применяют для разделения смеси аминокислот [17].

Целью данного исследования стала разработка простого способа получения аминокислотсодержащих производных сульфатированного арабиногалактана с использованием метода ионного обмена и изучение строения полученных продуктов методом ИК-спектроскопии. Модификацию сульфатированного арабиногалактана осуществляли аминокислотами различной природы: моноаминокарбоновой - глицином и диаминомонокарбоновой - орнитином. Выбор этих аминокислот в качестве моделей обусловлен не только их различной природой, но и их доступностью в химической практике и широком использовании в качестве терапевтических препаратов. Глицин наиболее широко применяется в психоневрологической клинической практике. Орнитин можно назвать родственником аргинина. Это своеобразная кислота, без которой невозможно стимулирование выделения инсулина и гормона роста $[1,2]$.

\section{Экспериментальная часть}

В качестве исходного сырья брали арабиногалактан древесины лиственницы сибирской (Larix sibirica Ledeb.) производства ООО «Химия древесины» (Иркутск, Россия) - препарат «ФиброларС».

Получение сульфатов AG осуществляли по методике [18] сульфатированием AG сульфаминовой кислотой в диоксане с последующим выделением сульфата AG в виде аммониевой соли (содержание серы 10.0-12.0\% масс.).

ИК-спектры сульфатированного AG, аминокислот и продуктов модификации сульфатированного AG аминокислотами сняты с использованием ИК-Фурье-спектрометра Tensor-27 (Bruker, Германия) в области длин волн 400-4000 см-1. Обработка спектральной информации проведена по программе OPUS (версия 5.0). Твердые образцы для анализа готовили в виде таблеток в матрице $\mathrm{KBr}$ (2 мг образца / 1000 мг KBr).

$$
-22-
$$


Содержание азота и серы в аммониевой соли сульфатированного AG и его аминокислотных производных осуществляли на элементном анализаторе Flash EA-1112 (Thermo Quest Italia).

Обнаружение аминокислот проводили нингидриновой реакцией [2]. Количественное определение содержания аминокислот в полученных аминокислотных производных AG в пересчете на содержание азота (\% масс), основанное на их взаимодействии с нингидрином, осуществляли фотоколориметрическим анализом [19].

Аминокислотсодержащие производные сульфатированного AG получали из его аммониевой соли методом ионного обмена с использованием ионообменной смолы КУ-2-8. Ионный обмен проводили в динамическом режиме. Предварительно ионообменную смолу КУ-2-8, вырабатываемую в промышленности в $\mathrm{Na}^{+}$-форме, переводили в $\mathrm{H}^{+}$-форму по стандартной методике [20]. Для этого через слой смолы КУ-2-8 в $\mathrm{Na}^{+}$-форме, помещенной в виде гомогенной смеси с дистиллированной водой в вертикальную стеклянную колонку диаметром 15-20 мм, вместимостью 50 мл, снабженную внизу краном, пропускали водный $2 \mathrm{M}$ раствор $\mathrm{HCl}$ до равных концентраций поступающего и вытекающего из бюретки раствора соляной кислоты. Затем промывали смолу дистиллированной водой до нейтральной реакции промывных вод. Далее сорбировали соответствующую аминокислоту на катионите. С этой целью пропускали $1 \mathrm{M}$ раствор аминокислоты через катионит до тех пор, пока концентрации поступающего и вытекающего раствора из ионообменной колонки раствора аминокислоты не станут равны. После этого промывали смолу дистиллированной водой, пропуская ее со скоростью 3-5 мл/мин. Промывали до тех пор, пока промывная вода не будет содержать соответствующую аминокислоту. Затем проводили ионный обмен катиона аммония в аммониевой соли сульфатированного AG на протонированную аминокислоту. Для этого через слой подготовленного катионита пропускали раствор $2,0-2,5$ г очищенной путем диализа аммониевой соли сульфатированного AG в 25 мл дистиллированной воды. После прохождения через колонку 25 мл раствора соли сульфатированного AG смолу в колонке промывали дистиллированной водой (2-3 раза по 25 мл). После пропускания второго объема воды определяли наличие аминокислоты при помощи качественной реакции. Собирали промывные жидкости и упаривали их досуха под вакуумом водоструйного насоса на ротационном испарителе. Температура перегонки не более $50{ }^{\circ} \mathrm{C}$. Определяли содержание серы и азота в полученном после высушивания в вакууме твердом остатке - аминокислотсодержащем производном сульфатированного AG.

\section{Результаты и обсуждение}

Процесс модификации сульфатированного AG аминокислотами осуществляли следующим образом:

а) катионит КУ-2-8, выпускаемый в промышленности в Na-форме, переводили в H-форму:

$\mathrm{R}-\mathrm{SO}_{3} \mathrm{Na}+\mathrm{H}^{+} \rightarrow \mathrm{R}-\mathrm{SO}_{3} \mathrm{H}+\mathrm{Na}^{+} ;$

$\mathrm{R}$ - матрица смолы КУ-2-8;

б) проводили сорбцию используемых аминокислот на катионите:

$\mathrm{R}-\mathrm{SO}_{3} \mathrm{H}+\mathrm{Am} \rightarrow \mathrm{R}-\mathrm{SO}_{3}{ }^{-}[\mathrm{AmH}]^{+}$,

$\mathrm{Am}$ - соответствующая аминокислота; 
в) осуществляли ионный обмен катионов аммония в сульфатированном AG на катион протонированной аминокислоты:

$\mathrm{R}-\mathrm{SO}_{3}-[\mathrm{AmH}]^{+}+\mathrm{AG}-\mathrm{OSO}_{3}{ }^{-} \mathrm{NH}_{4}{ }^{+} \rightarrow \mathrm{R}-\mathrm{SO}_{3}{ }^{-} \mathrm{NH}_{4}{ }^{+}+\mathrm{AG}-\mathrm{OSO}_{3}{ }^{-}[\mathrm{AmH}]^{+}$.

Ионный обмен проводили в динамическом режиме. Содержание серы в исходной аммониевой соли сульфатированного AG составляло $10.1 \%$ (масс.).

Введение аминокислот в структуру сульфатированного AG было подтверждено нингидриновой реакцией, данными результатов элементного анализа и ИК-спектроскопии.

Результаты элементного анализа продуктов модифицирования сульфатированного AG представлены в табл. 1.

Согласно результатам элементного анализа (табл. 1) в составе продуктов модификации сульфатированного AG аминокислотами на 1 моль сульфатных групп AG приходится 1 моль аминокислоты.

Из данных ИК-спектроскопического исследования продуктов модифицирования сульфатированного AG аминокислотами выявлены структурные изменения в продукте реакции по сравнению с исходными соединениями.

Основным отличием ИК-спектра продукта модифицирования сульфатированного AG (рис. 1) от ИК-спектра глицина [21] выступает отсутствие полосы поглощения в области $2122 \mathrm{~cm}^{-1}$, появление которой связывают с наличием биполярной ионной структуры глицина [22].

Также в ИК-спектре указанного продукта вместо полосы поглощения в области $1605 \mathrm{~cm}^{-1}$, соответствующей валентным колебаниям $\mathrm{C}-\mathrm{O}$-связей карбоксилат-аниона, возникает полоса поглощения $\mathrm{C}=\mathrm{O}$-связей недиссоциированной карбоксильной группы в области $1756 \mathrm{~cm}^{-1}$. Кроме того, появляются полосы поглощения, соответствующие валентным колебаниям гидроксильных групп в области $3500 \mathrm{~cm}^{-1}$ и асимметричным валентным колебаниям $\mathrm{O}=\mathrm{S}=\mathrm{O}$-групп в области $1253 \mathrm{~cm}^{-1}$ [23]. По сравнению с ИК-спектром аммониевой соли сульфатированного AG [18] отсутствует интенсивная полоса поглощения в области $1450 \mathrm{~cm}^{-1}$, соответствующая колебаниям N-Н-связей катиона аммония.

На основании этих данных можно предположить, что в результате реакции образуется производное глицина и сульфатированного AG следующего строения:

$$
\mathrm{AG}-\mathrm{OSO}_{3}^{-}\left[\mathrm{H}_{3} \stackrel{+}{\mathrm{N}}-\mathrm{CH}_{2}-\mathrm{COOH}\right]
$$

Одно из отличий ИК-спектров продуктов модифицирования сульфатированного AG орнитином (рис. 2) от спектра гидрохлорида орнитина [23] - отсутствие полосы поглоще-

Таблица 1. Результаты элементного анализа сульфатированного арабиногалактана, модифицированного аминокислотами

\begin{tabular}{|l|c|c|c|c|}
\hline \multirow{2}{*}{$\begin{array}{c}\text { Аминокислота, используемая для } \\
\text { модификации сульфатированного AG }\end{array}$} & \multicolumn{2}{|c|}{$\begin{array}{c}\text { Результаты элементного } \\
\text { анализа }\end{array}$} & \multicolumn{2}{c|}{$\begin{array}{c}\text { Сотношение S:N, } \\
\text { моль/моль }\end{array}$} \\
\cline { 2 - 5 } & $\mathrm{S} \%$ (масс.) & $\mathrm{N} \%$ (масс.) & рассчитано & получено \\
\hline Глицин & 8,3 & 3,5 & $1 / 1$ & $1 / 1$ \\
\hline Орнитин & 7,3 & 6,4 & $1 / 2$ & $1 / 2$ \\
\hline
\end{tabular}




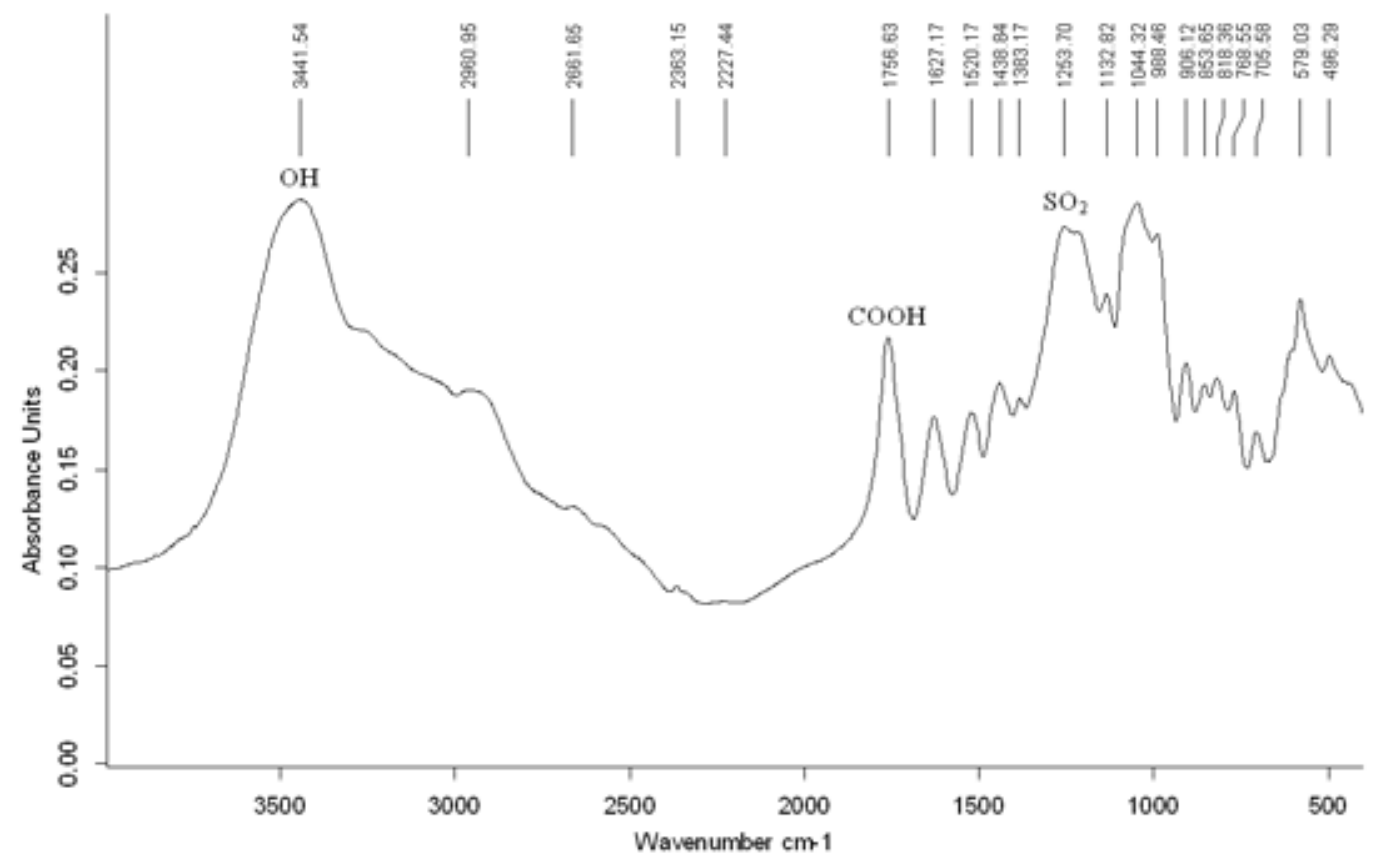

Рис. 1. ИК-спектр продукта взаимодействия глицина и сульфатированного арабиногалактана

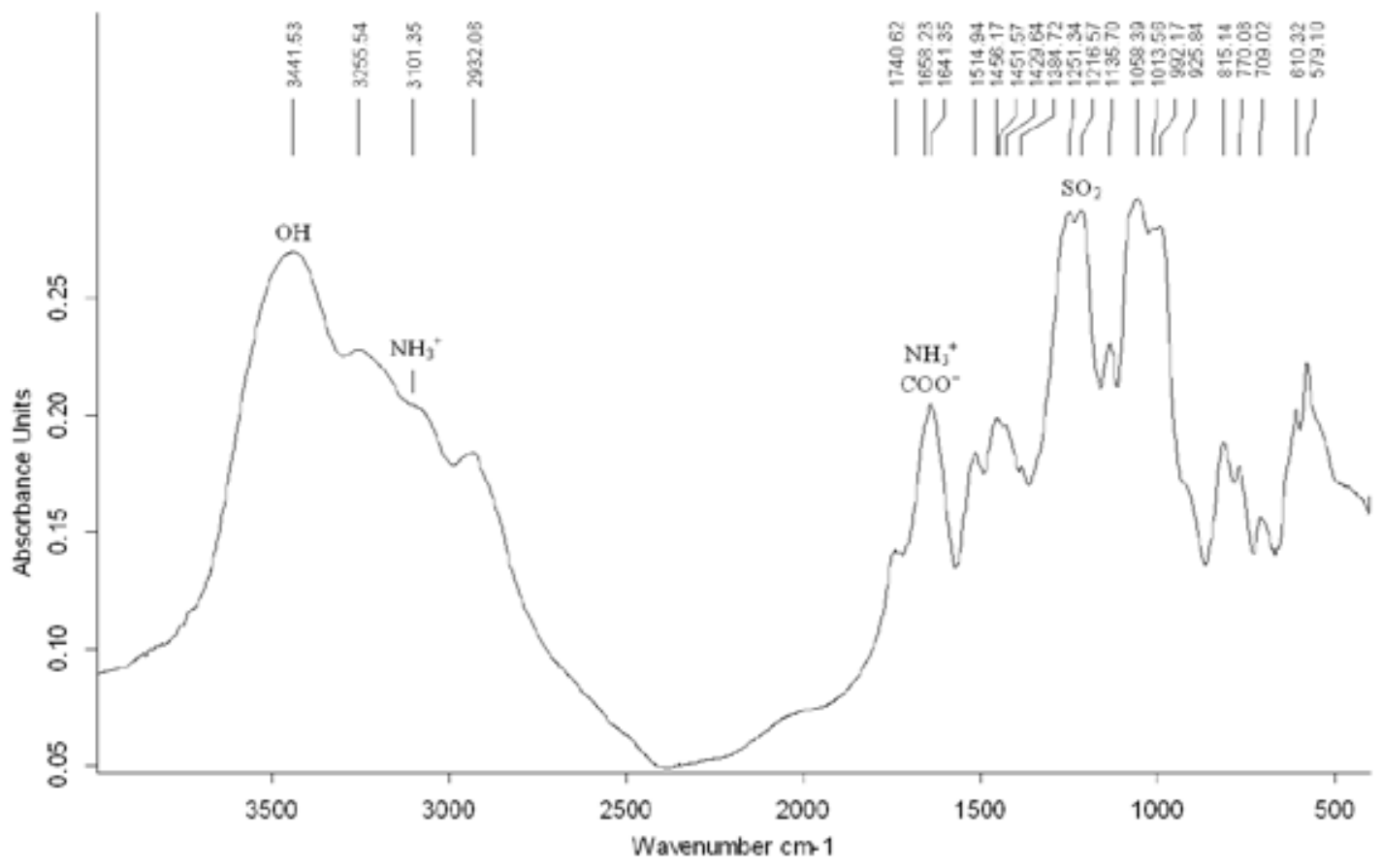

Рис. 2. ИК-спектр продукта взаимодействия орнитина и сульфатированного арабиногалактана 
ния в области 2057 см$^{-1}$, которую приписывают большинству гидрохлоридов аминокислот [22].

В ИК-спектре орнитинсодержащего производного сульфата AG присутствует слабая полоса поглощения в области $3101 \mathrm{~cm}^{-1}$, которая соответствует валентным колебаниям $\mathrm{NH}_{3}{ }^{+}$. По сравнению с ИК-спектром аммониевой соли отсутствует интенсивная полоса поглощения в области $1450 \mathrm{~cm}^{-1}$, соответствующая деформационным колебаниям N-Н-связей катиона аммония. Полосы поглощения в области 1658-1514 $\mathrm{cm}^{-1}$ можно отнести к полосам поглощения $\mathrm{COO}^{-}$и $\mathrm{NH}_{3}{ }^{+}$; кроме того, наблюдается слабая полоса поглощения (в виде выступа) в области $1740 \mathrm{~cm}$ ${ }^{1}$, которая должна соответствовать валентным колебаниям $\mathrm{C}=\mathrm{O}$ недиссоциированной карбоксильной группы. В спектре орнитинсодержащего производного сульфата AG в отличие от ИКспектра гидрохлорида орнитина [23] наблюдается широкая полоса в области 3442 и $2933 \mathrm{~cm}^{-1}$, в которой происходит наложение полос поглощения, соответствующих валентным колебаниям $\mathrm{N}-\mathrm{H}-$ связей в $\mathrm{NH}_{3}{ }^{+}, \mathrm{NH}_{2}$, и O-Н-связей. Как и в спектре аммониевой соли сульфатированного $\mathrm{AG}$, присутствует полоса поглощения высокой интенсивности в области около 1251-1216 см${ }^{-1}$, соответствующая валентным колебаниям $\mathrm{O}=\mathrm{S}=\mathrm{O}$-связей [24]. Следует отметить, что в соответствии с ИК-спектром этого производного протонированию подвергается как карбоксильная группа, так и вторая аминогруппа орнитина.

На основании полученных данных ИК-спектроскопии и элементного анализа орнитинсодержащее производное сульфатированного AG можно представить в виде следующих структур:

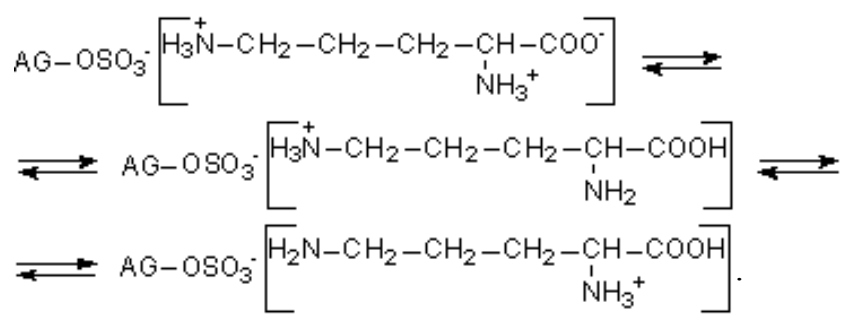

\section{Заключение}

Впервые получены глицин- и орнитинпроизводные сульфатированного AG с использованием метода ионного обмена.

Состав и строение синтезированных производных сульфатированного AG с аминокислотами подтверждены качественными реакциями на соответствующие аминокислоты, данными результатов элементного анализа и ИК-спектроскопии.

Методом ИК-спектроскопии установлено различие структур полученных глицин- и орнитинпроизводных сульфатированного AG. В орнитинпроизводном сульфатированного AG возможно присутствие как неионизированной, так и ионизированной карбоксильной группы. Присутствие неионизированной аминогруппы предполагает одновременное протонирование обеих аминогрупп.

\section{Благодарности}

В работе использованы приборы Красноярского регионального центра коллективного пользования СО РАН. 


\section{Список литература}

1. Машковский М.Д. Лекарственные средства. М.: Новая волна, 2012, 1216 с. [Mashkovsky M.D. Medicinal drugs. M.: New wave, 2012. 1216 pp. (in Russ.)]

2. Гараева С.Н., Редкозубова Г.И., Постолати Г.В. Аминокислоты в живом организме. Кишинев: Акад. наук Молдовы, Ин-т физиологии и санокреатологии, 2009, 552 с. [Garaeva S.N., Redkozubova G.I., Postolati G.V. Amino acids in living organism. Kishinev: Academy of Sciences of Moldova, Institute of Physiology and Sanocreatology, 2009. 552 pp. (in Russ.)]

3. Reis R.L., Neves N.M., Mano J.F., Gomes M.E., Marques A.P., Azevedo H.S. Natural-Based Polymers for Biomedical Applications. Cambridge: Woodhead Publishing Limited, 2008, 832 p.

4. Беляев Е.Ю. Новые медицинские материалы на основе модифицированных полисахаридов (Обзор). Хим.-фарм. журн. 2000. Т. 34(11), С. 36-41. [Belyaev E. Yu. New medical materials based on modified polysaccharide (Review). Pharmaceutical Chemistry Journal 2000. Vol. 34(11), P. 607-612.].

5. Ehrenfreund-Kleinman T., Golenser J., Domb A.J. Conjugation of amino-containing drugs to polysaccharides by tosylation: amphotericin B-arabinogalactan conjugates. Biomaterials. 2004. Vol. 25(15), P. 3049-3057.

6. Maiti S., Ranjit S., Sa B. Polysaccharide-based graft copolymers in controlled drug delivery. Int. J. Pharm. Tech. Res. 2010. Vol. 2(2), P. 1350-1358.

7. Костыро Я.Н., Силизерцева О.А., Искра А.И. Петрова Е.Н., Корякина Л.Б., Верещагина С.А., Фадеева Т.Б., Алексеев К.В., Гуменникова Е.Н., Костыро В.В., Ганенко Т.В., Станкевич В.К., Трофимов Б.А. Перспективы разработки и применения в медицинской практике препаратов на основе гепариноидов. Бюл. ВСНЦ СО РАМН. 2011. Т. 80(4), С. 249-254. [Kostyro Ya.A., Silizertseva O.A., Iskra A.I., Petrova E.N., Koryakina L.B., Vereshchagina S.A., Fadeeva T.V., Alekseev K.V., Gumennikova E.N., Kostyro V.V. Ganenko T.V., Stankevich V.K., Trofimov B.A. Prospects of development and use of heparinoid-based preparations in medical practice. Bulletin of the East Siberian Scientific Center SB RAMS. 2011. Vol. 80(4), P. 249-254. (in Russ.)].

8. Медведева Е.Н., Бабкин В.А., Остроухова Л.А. Арабиногалактан лиственницы - свойства и перспективы использования (обзор). Химия растительного сырья 2003. (1), С. 27-37. [Medvedeva E.N., Babkin V.A., Ostroukhova L.A. Arabinogalactan from larch - properties and prospects. Chemistry of plant raw materials 2003. (1), P. 27-37. (in Russ.)].

9. Васильева Н.Ю., Левданский А.В., Карачаров А.А., Мазурова Е.В., Бондаренко Г.Н., Левданский В.А., Казаченко А.С., Кузнецов Б.Н. Изучение строения продуктов сульфатирования арабиногалактана из древесины лиственницы хлорсульфоновой кислотой в пиридине. Журнал СФУ. Химия. 2014. Т. 7(4), С. 547-555. [Vasilyeva N.Yu, Levdansky A.V., Karacharov A.A., Mazurova E.V., Bondarenko G.N., Levdansky V.A., Kazachenko A.S., Kuznetsov B.N. Study of structure of product's obtained by sulfation of arabinogalactan from larch wood with chlorosulfonic acid in pyridine. J. SFU. Chemistry. 2014. Vol. 7(4), P.547-555. (in Russ.)]

10. Jacues L.B. Heparins - anionic polyelectrolyte drugs. Pharmacol. Rev. 1979. Vol. 31(2), P. 99-166.

11. DeAngelis P.L., Glabe C.G. Role of basic amino acids in the interaction of bindin with sulfated fucans. Biochem. 1988. Vol. 27(21), P. 8189-8194. 
12. Крылов В.Б., Устюжанина Н.Е., Нифантьев Н.Э. Синтез низкомолекулярных углеводных миметиков гепарина. Биоорган. химия. 2011. Т. 37(6), С. 745-779. [Krylov V.B., Ustyuzhanina N.E., Nifantiev N.E. Synthesis of low-molecular-weight carbohydrate mimetics of heparin. Russ. J. Bioorganic Chem. 2011. Vol. 37(6), P. 672-706.].

13. Kweon D.-K., Song S.-B., Park Y.-Y. Preparation of water-soluble chitosan/heparin complex and its application as wound healing accelerator. Biomaterials. 2003. Vol. 24(9), P. 1595-1601.

14. Fromm J.R., Hileman R.E., Caldwell E.E.O., Weiler J.M., Linhardt R.J. Differences in the interaction of heparin with arginine and lysine and the importance of these basic amino acids in the binding of heparin to acidic fibroblast growth factor. Arch. Biochem. Biophys. 1995. Vol. 323(2), P. 279-287.

15. Патент 2448717 РФ. Исаев В.А., Ляпина Л.А., Оберган Т.Ю., Николаева Л.С., Семёнов А.Н., Ершов А.А. Способ получения антикоагулянтно-фибринолитического средства на основе гепарина. Опубл. 27.04.2012. [Patent 2448717 RU. Isaev V.A., Lyapina L.A., Obergan T.Yu., Nikolaeva L.S., Semenov A.N., Ershov A.A. Method for making anticoagulant-fibrinolytic heparin preparation. Publ. Date 27.04.2012.].

16. Rabenstein D.L. Heparin and heparan sulfate: structure and function. Nat. Prod. Rep. 2002. Vol. 19(3), P. 312-331.

17. Csapó J., Albert Cs., Lóki K., Csapó-Kiss Zs. Separation and determination of the amino acids by ion exchange column chromatography applying postcolumn derivatization. Acta Univ. Sapientiae, Alimentaria. 2008. Vol. 1. P. 5-29.

18. Vasil'eva N.Yu., Levdansky A.V., Kuznetsov B.N., Skvortsova G.P., Kazachenko A.S., Djakovitch L., Pinel C. Sulfation of arabinogalactan by sulfamic acid in dioxane. Russ. J. Bioorg. Chem. 2015. Vol. 41(7), P. 725-731.

19. Jones D.L., Owen A.G., Farrar J.F. Simple method to enable the high resolution determination of total free amino acids in soil solutions and soil extracts. Soil. Biol. Biochem. 2002. Vol. 34(12), P. 1893-1902.

20. Zagorodni A.A. Ion Exchange Materials. Properties and Applications. Amsterdam; London: Elsevier, 2007, 477 p.

21. Dillip G.R., Raghavaiah P., Mallikarjuna K., Madhukar Reddy C., Bhagavannarayana G., Ramesh Kumar V., Deva Prasad Raju B. Crystal growth and characterization of $\gamma$-glycine grown from potassium fluoride for photonic applications. Spectrochim. Acta Mol. Biomol. Spectrosc. 2011. Vol. 79(5), P. 1123-1127.

22. Bellamy L.J. Advances in Infrared Group Frequencies. London: Methuen, 1968, 328 p.

23. Balakrishnan T., Ramamurthi K. Crystal growth, structural, optical, mechanical and thermal properties of a new nonlinear optical single crystal: L-Ornithine monohydrochloride. Spectrochim. Acta Mol. Biomol. Spectrosc. 2009. Vol. 72(2), P. 269-273.

24. Васильева Н.Ю., Левданский А.В., Казаченко А.С., Дьякович Л., Пинель К., Кузнецов Б.Н. Сульфатирование механоактивированного арабиногалактана комплексом серный ангидрид - пиридин в среде пиридина. Журнал СФУ. Химия. 2013. Т. 6(2), С. 158-169. [Vasilyeva N.Yu, Levdansky A.V., Kazachenko A.S., Djakovitch L., Pinel C., Kuznetsov B.N. Sulfation of mechanically activated arabinogalactan by complex sulfuric anhydride - pyridine in pyridine medium. J. SFU. Chemistry. 2013. Vol. 6(2), P.158-169. (in Russ.)]. 